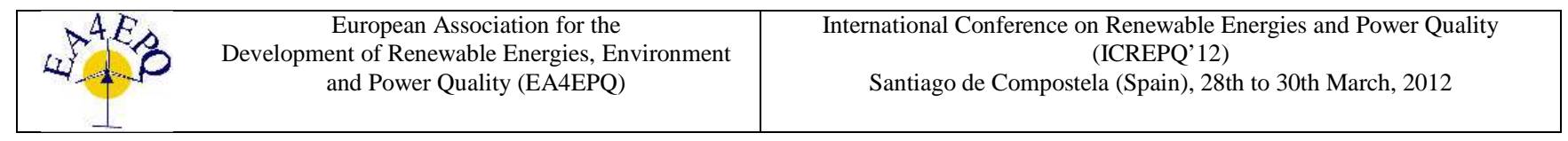

\title{
In-field monitoring and numerical parametric analysis of a small size adsorption solar cooling plant in Italy
}

\author{
M. Simonetti ${ }^{1}$, L. Degiorgis ${ }^{1}$, G.V. Fracastoro ${ }^{1}$, A. Ghafoor ${ }^{1}$ and M. E. Arboit $^{2}$ \\ ${ }^{1}$ Energy Department DENERG \\ Polytechnic of Turin \\ c.so Duca degli Abruzzi 24, 10129 Turin (ITALY) \\ Phone/Fax number:+0039 0110904435/4499, e-mail: marco.simonetti@polito.it \\ ${ }^{2}$ INCIHUSA Conicet Mendoza \\ Mendoza (ARGENTINA) \\ marboit@mendoza-conicet.gob.ar
}

\begin{abstract}
Solar cooling of small buildings represents a very interesting potential market, still underdeveloped and characterized by a wide range of uncertainties, both on the technological and the economical side. Actually, there are a few low size ready-to-market adsorption/absorption chillers and their costs are significantly higher than technically mature compression systems. The combination of solar thermal systems with solar assisted chillers needs a thorough design stage to be correctly optimized and this may turn out unaffordable for a low size project.
\end{abstract}

A monitoring campaign has been carried on a new building (PUEEL - Prototipo Uffici ad Elevata Efficienza in Legno, High Efficiency Wooden Office Prototype) realized at the facilities of IPLA $^{1}$ in Turin, Italy. The building has a wooden highly insulated envelope, controlled mechanical ventilation with thermodynamic heat recovery, radiant heating/cooling. A solar thermal collector field is integrated in the building roof (Fig.1), used both for the building heating and cooling demand, thanks to a $9 \mathrm{~kW}$ adsorption chiller.

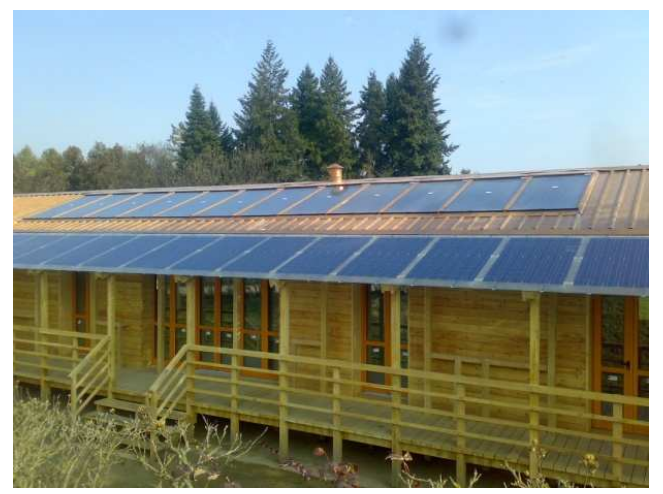

Fig. 1: Picture of the new building with integrated solar thermal (up) and photovoltaic collectors (bottom)

\footnotetext{
${ }^{1}$ IPLA is a public Research Institution dealing with plants, wood and environment
}

Dynamic simulations of the system, using software Polysun (C) for solar cooling plant and EnergyPlus (C) for building demand assessment, have also been carried on and compared with in-field measurements. The validated model has been used for a parametric evaluation of the effects of the installation of different components and control strategies.

\section{Key words}

Solar cooling, in-field measurements, parametric simulation, solar fraction

\section{Introduction}

Solar cooling has been theoretically explored during the ' 80 s' as a result of the spread out of solar thermal technologies, but a small number of plants have been actually installed and measured so far.

Actually, the use of solar thermal collectors for cooling purposes - coupled with winter ambient heating, would widen their application beyond traditional Domestic Hot Water systems.

The UE's “20-20-20” task has brought new attention to thermal exploitation of solar source.

The solar cooling system of PUEEL building at IPLA institute in Turin, Italy, is the first of this kind in the nearly 1-Million inhabitants city, and one of the few of entire Italy.

During the design stage, an adsorption chiller with a low value $\left(70^{\circ} \mathrm{C}\right)$ of nominal driving heat temperature has been selected and coupled to water double-glazed solar collectors. Due to budget reasons, during the construction phase this type of collector has been replaced with single glazed one.

Monitoring has started on August 21, 2011, and has been regularly carried on since then. It should be mentioned 
that August 21 has been the hottest day in the year and September 2011 has been the warmest September in Turin from 1753, with average (day and night) temperature of $23.1^{\circ} \mathrm{C}$ and daily peaks around $30^{\circ} \mathrm{C}$. The system has worked in cooling mode till October, 10.

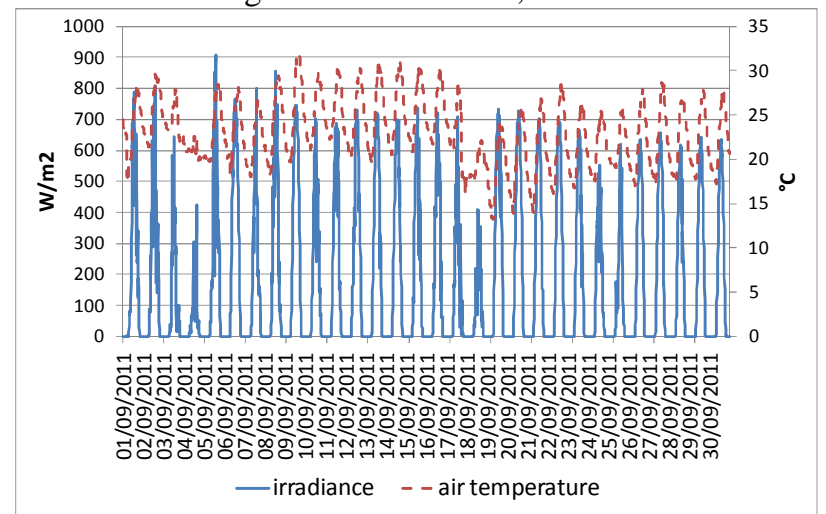

Fig. 2: Weather data for Turin September 2011

\section{Description of the monitored plant}

\section{A. Plant scheme}

The PUEEL building solar cooling system is based on a simple scheme (Fig. 3). The $28 \mathrm{~m}^{2}$ solar collector field supplies heat to a $4 \mathrm{~m}^{3}$ water storage tank. The storage tank is fitted with a thermostatically controlled auxiliary heat source (electrical resistance). A $9 \mathrm{~kW}$ peak power chiller, based on an adsorption cycle with zeolite is driven by the heat flow coming from the storage tank and refrigerates the building by mean of a radiant panel cooling system. A chilled water storage tank of $0.5 \mathrm{~m}^{3}$ is installed on the cooling circuit. Heat rejection from the chiller is based on a fan driven dry cooler.

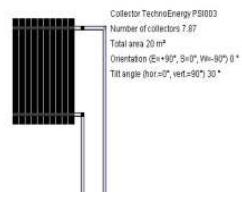

Solar loop
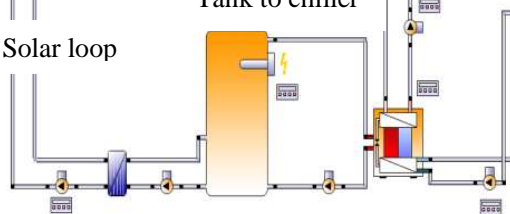

屋

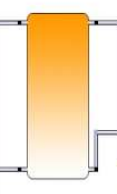

Radiant coolin panel circuit

Fig. 3: Schematics of the plant (graphics from Polysun 5.3)

\section{B. Monitoring system}

Table I shows the analogical input data of the monitoring system.

Table I. - Plant monitored variables

\begin{tabular}{|c|c|c|c|}
\hline Circuit & Variable & Unit & Precision \\
\hline Solar loop & $\begin{array}{l}\text { Water return } \\
\text { temperature }\end{array}$ & {$\left[{ }^{\circ} \mathrm{C}\right]$} & \pm 0.5 \\
\cline { 2 - 4 } & $\begin{array}{c}\text { Water supply } \\
\text { temperature }\end{array}$ & {$\left[{ }^{\circ} \mathrm{C}\right]$} & \pm 0.5 \\
\cline { 2 - 4 } & Flow rate & {$\left[\mathrm{m}^{3} / \mathrm{h}\right]$} & \pm 0.01 \\
\hline Tank to chiller & $\begin{array}{l}\text { Water return } \\
\text { temperature }\end{array}$ & {$\left[{ }^{\circ} \mathrm{C}\right]$} & \pm 0.5 \\
\cline { 2 - 4 } & Water supply & {$\left[{ }^{\circ} \mathrm{C}\right]$} & \pm 0.5 \\
\hline
\end{tabular}

\begin{tabular}{|c|c|c|c|}
\hline & temperature & & \\
\cline { 2 - 4 } & Flow rate & {$\left[\mathrm{m}^{3} / \mathrm{h}\right]$} & \pm 0.01 \\
\hline $\begin{array}{c}\text { Radiant } \\
\text { cooling panels }\end{array}$ & $\begin{array}{l}\text { Water return } \\
\text { temperature }\end{array}$ & {$\left[{ }^{\circ} \mathrm{C}\right]$} & \pm 0.5 \\
\cline { 2 - 4 } & $\begin{array}{c}\text { Water supply } \\
\text { temperature }\end{array}$ & {$\left[{ }^{\circ} \mathrm{C}\right]$} & \pm 0.5 \\
\cline { 2 - 4 } & Flow rate & {$\left[\mathrm{m}^{3} / \mathrm{h}\right]$} & \pm 0.01 \\
\hline Heat rejection & $\begin{array}{l}\text { Water return } \\
\text { temperature }\end{array}$ & {$\left[{ }^{\circ} \mathrm{C}\right]$} & \pm 0.5 \\
\cline { 2 - 4 } & $\begin{array}{l}\text { Water supply } \\
\text { temperature }\end{array}$ & {$\left[{ }^{\circ} \mathrm{C}\right]$} & \pm 0.5 \\
\cline { 2 - 4 } & Flow rate & {$\left[\mathrm{m}^{3} / \mathrm{h}\right]$} & \pm 0.01 \\
\hline
\end{tabular}

Table II. - Meteorological monitored variables (hourly samples)

\begin{tabular}{|c|c|}
\hline Sun & $\begin{array}{c}\text { Global } \\
\text { horizontal } \\
\text { irradiance }\end{array}$ \\
\hline Outdoor air & Air temperature \\
\cline { 2 - 3 } & Air humidity \\
\cline { 2 - 3 } & Wind speed \\
\cline { 2 - 3 } & Wind direction \\
\hline
\end{tabular}

\section{Monitoring results}

\section{A. Global performance}

The global efficiency of the system, $\mathrm{COP}_{\text {sol }}$, defined as:

where:

$$
C O P_{\text {sol }}=\frac{Q_{C}}{H_{\text {coll }} * A_{\text {coll }}}
$$

$\mathrm{Q}_{\mathrm{C}}$ : cooling energy produced $[\mathrm{kWh}]$

$\mathrm{H}_{\text {coll }}$ : global solar radiation on the collector plane $\left[\mathrm{kWh} / \mathrm{m}^{2}\right]$

$\mathrm{A}_{\text {coll }}$ : net aperture area of collector field $\left[\mathrm{m}^{2}\right]$

During the monitoring time the auxiliary electrical heater was set off, all thermal power coming from the sun.

$\mathrm{COP}_{\text {sol }}$ has been derived using daily values and it is shown for August 21 to September 23 in figure 4, with the daily value of chiller $\mathrm{COP}_{\mathrm{ch}}$, defined as:

$$
C O P_{c h}=\frac{Q_{C}}{Q_{t h}}
$$

where $Q_{t h}$ is the thermal energy from the storage to the chiller [kWh]

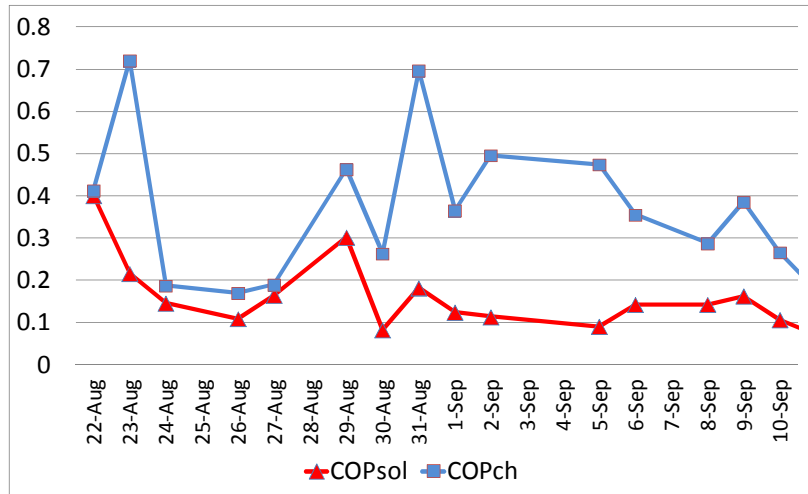

Fig. 4: daily $\mathrm{COP}_{\text {sol }}$ and $\mathrm{COP}_{\mathrm{ch}}$. 
The $\mathrm{COP}_{\text {ch }}$ presents a wide spread of values, from 0.1 to 0.7 , while $\mathrm{COP}_{\text {sol }}$ is within a range of 0.1-0.4, with an average value of nearly 0.14 .

In terms of power profile, the day of august 26 , for example, is shown in Figure 5.

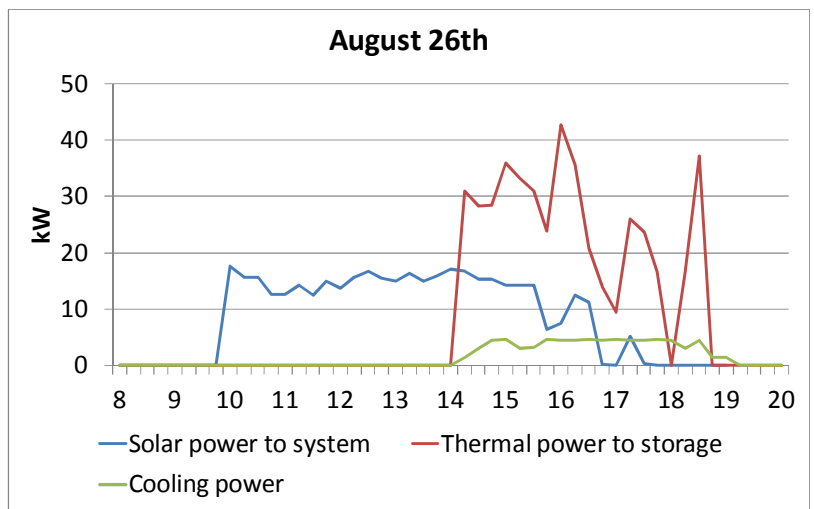

Fig. 5: August 26, hourly measured thermal powers.

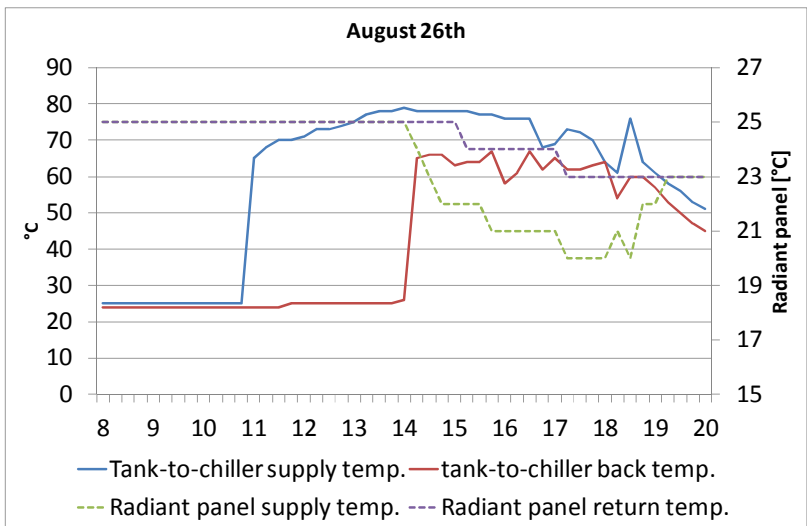

Fig. 6: August 26, hourly measured temperatures for thermal driving circuit and radiant panel cooling circuit (both constant flow rate)

Figure 5 shows how the storage is being loaded from 10 a.m. to 14 , while it is used as heat source during the afternoon. Its sizing should take into account the eventual shift of thermal power from peak solar radiation to peak cooling demand times.

Figure 6 reports typical range of operability of the system, in term of temperatures on the two sides of the chiller, tank to chiller circuit, and radiant cooling panels circuit. The inlet temperature to the chiller, coming from the storage, is around $80^{\circ} \mathrm{C}$, while its nominal value is $70^{\circ} \mathrm{C}$. During the evening, when solar power lowers down, the temperature of the storage decreases too, and this will lead to a lower $\mathrm{COP}_{\text {ch value than nominal. }}$

The daily solar energy collected and heat to the chiller is illustrated in Figure 7. The difference between these data includes both tank losses and tank internal energy variations. In the long term they account only for tank losses.

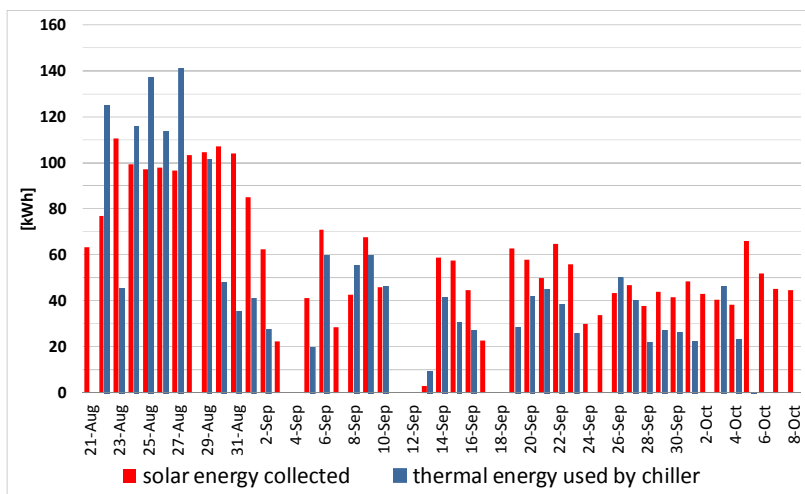

Fig. 7 Energy balance of the system: solar energy collected compared to heat used by the chiller

Figure 8 reports the net daily balance between solar energy collected and heat to the chiller and its cumulated value, compared to the cumulated daily cooling energy of the system.

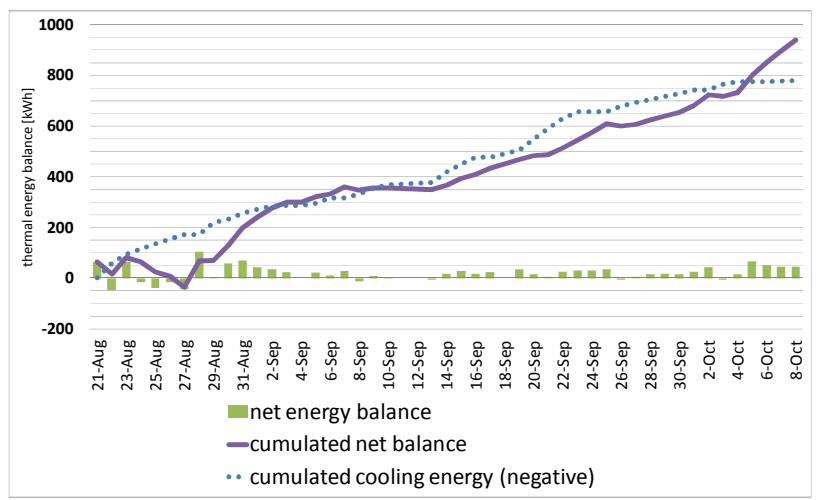

Fig. 8: Energy balance of the system: daily balance, cumulate curve of daily balance compared to cumulated cooling energy (to be considered with negative sign)

The overall tank losses equal the cooling energy, thus suggesting an oversizing of the solar collector circuit.

Figure 8 also suggests that the system efficiency is significantly low, since tank losses are of the same order of magnitude of the building cooling energy.

Assuming that (as far as the auxiliary heater is off):

$$
\operatorname{COP}_{\text {sol }}=\eta_{\text {Bos }} \cdot \eta_{\text {coll }} \cdot \operatorname{COP} P_{c h}
$$

where $\eta_{\text {воs }}$ is the balance of system efficiency, it is possible to calculate this efficiency, which takes into account overall thermal losses of the system, excluding the solar circuit.

To do so, it is necessary to evaluate the efficiency of solar collectors. The measured mean value of $\eta_{\text {coll }}$ (solar collector efficiency) is 0.45 , while the value calculated from catalogue performance data, using as input the $\mathrm{x}$ parameter calculated through the measured water temperature and weather data, is 0.52 . Figure 9 reports 19 days of daily averaged measured $\eta_{\text {coll }}$ values compared to expected ones. 


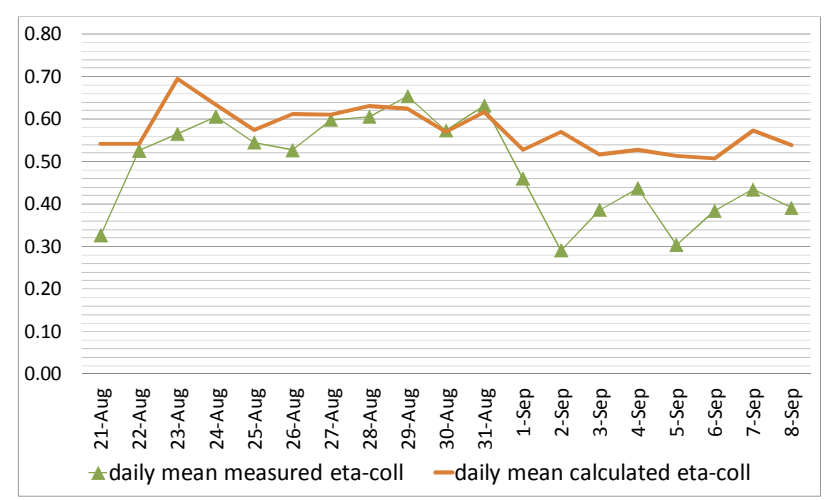

Fig. 9: daily mean solar collector efficiency of central hours of the days 21 August - 8 September

Considering these values, the mean efficiency of the system $\eta_{\text {syst }}$ is 0.82 , meaning that almost $20 \%$ of the collected solar energy is lost.

\section{Comments on monitoring results}

The monitoring activity has pointed out some key points, relevant to the evaluation of the performance of the system:

- The thermal storage plays a very important role and its sizing should consider the expected shift of solar irradiation and cooling demand profiles.

- The averaged daily values of $\mathrm{COP}_{c h}$ present a wide spread, likely due to a too low sampling frequency of the monitoring system. Mean values are, nonetheless, on the same order of the credited official values. Adsorption chiller presents unsteady performance, for its own nature of intermittent cyclic system. The assessment of the chiller instantaneous performance needs a sampling time-step lower than one minute.

- The solar thermal system efficiency presents some discrepancies with catalogue values, but average values are only slightly lower than expected ones.

- The averaged daily values of $\mathrm{COP}_{\text {sol }}$ is about 0.14 . This value, considering the mean values of $\mathrm{COP}_{\mathrm{ch}}$ and of $\eta_{\text {coll }}$, is due to an unexpected low value of BOS efficiency. A significant part of the collected solar energy is lost. This can suggest an oversizing of the solar collector system related to the cooling demand in the monitored period.

\section{Comparison with numerical simulations}

Polysun software has been used to simulate the hourly performance of the system.

Since building demand dynamics are not accurately modelled in Polysun, an auxiliary model of the building has been realized and pre-processed using EnergyPlus. Data from this simulation have been used to set the Polysun simplified building model, in order to obtain the best fit with simulation. These data have been later compared with the measured cooling energy demand of the building.

In order to compare the Polysun model with the measured data a specific set of boundary conditions has been input in the program, including:

- measured weather data for September 2011

- measured cooling demand of the building for September 2011
- $\quad$ monitored using profile of the building

\begin{tabular}{|c|c|c|c|c|c|}
\hline & $\boldsymbol{\eta}_{\text {coll }}$ & $\mathbf{C O P}_{\text {ch }}$ & $\mathbf{C O P}_{\text {sol }}$ & $\begin{array}{c}\text { building } \\
\text { cooling } \\
\text { energy } \\
\mathbf{Q}_{\mathbf{c}}\end{array}$ & $\begin{array}{c}\text { solar } \\
\text { energy } \\
\text { collected } \\
\mathbf{Q}_{\text {sol }}\end{array}$ \\
\hline & - & - & - & $k W h(-)$ & $k W h$ \\
\hline $\mathrm{S}$ & 0.42 & 0.39 & 0.16 & 524 & $1^{\prime} 632$ \\
\hline $\mathrm{M}$ & 0.45 & 0.38 & 0.14 & 550 & $1^{\prime} 904$ \\
\hline
\end{tabular}

Table III. - comparison of simulated (S) and measured (M)

average performance and energy balance terms (September 2011)

Simulated values are generally in good agreement with measured ones. The effect of system losses in the real case is more significant.

\section{Results of parametric analysis}

A parametric analysis has been performed using the validated Polysun model.

Main task of this work is to verify the effect of the application of different

- types of solar collectors,

- volume storage,

- control set-points, and

- heat rejection sink temperatures.

The simulation of different cases were performed on a TRY weather data.

Figure 10 reports a comparison between performance of three type of collectors (Table IV).

\begin{tabular}{|c|l|l|}
\hline \multirow{3}{*}{ Single Glazed } & $\eta_{0}$ & 0.839 \\
\cline { 2 - 3 } & $\mathrm{a}_{1}$ & $4.42 \mathrm{~W} / \mathrm{m}^{2} / \mathrm{K}$ \\
\cline { 2 - 3 } & $\mathrm{a}_{2}$ & $0.0123 \mathrm{~W} / \mathrm{m}^{2} \mathrm{~K}^{2}$ \\
\hline \multirow{3}{*}{ Double Glazed } & $\eta_{0}$ & 0.811 \\
\cline { 2 - 3 } & $\mathrm{a}_{1}$ & $2.71 \mathrm{~W} / \mathrm{m}^{2} / \mathrm{K}$ \\
\cline { 2 - 3 } & $\mathrm{a}_{2}$ & $0.01 \mathrm{~W} / \mathrm{m}^{2} \mathrm{~K}^{2}$ \\
\hline Vacuum Tubes & $\eta_{0}$ & 0.739 \\
\cline { 2 - 3 } & $\mathrm{a}_{1}$ & $1.08 \mathrm{~W} / \mathrm{m}^{2} / \mathrm{K}$ \\
\cline { 2 - 3 } & $\mathrm{a}_{2}$ & $0.0056 \mathrm{~W} / \mathrm{m}^{2} \mathrm{~K}^{2}$ \\
\hline
\end{tabular}

Table IV. - efficiency parameters of the three simulated collectors

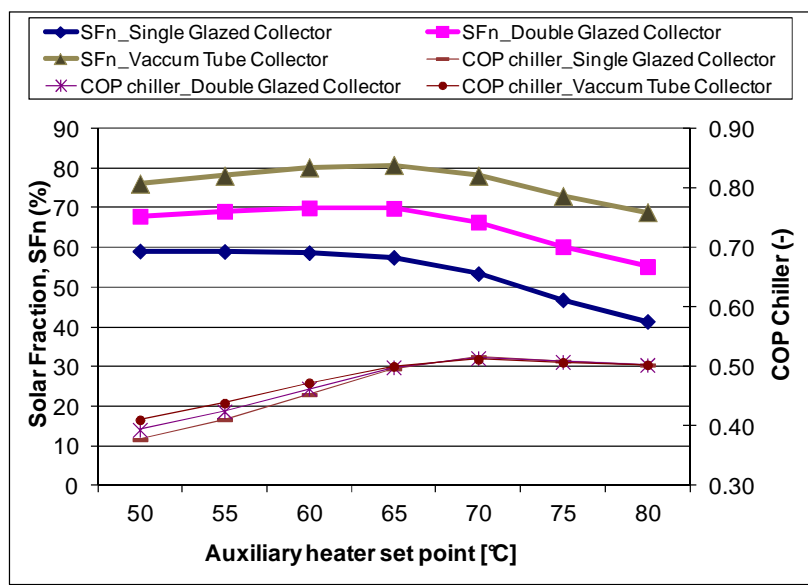

Fig. 10: Solar fraction as a function of the auxiliary heater setpoint for three types of solar collectors

The application of a double glazed collector, considering the same heat rejection system (dry cooling) and same 
storage temperature set-point, would have increased the solar fraction by almost $20 \%$, and another $20 \%$ would have been gained with the installation of vacuum tubes high performance collectors.

When the set-point temperature for auxiliary heater increases, the average $\mathrm{COP}_{c h}$ increases too, because it is served by a higher temperature for a larger amount of time. In the area between $50^{\circ}$ and $65^{\circ} \mathrm{C}$ the system fitted with single glazed collector will have a reduction of solar fraction, while high performance double glazed and vacuum tube will perform better.

During the measurements Solar Fraction was permanently equal to $100 \%$ because the auxiliary system was off, while in this case its values range between 40 and $80 \%$, with a maximum value around $65{ }^{\circ} \mathrm{C}$ for the two better quality collectors.

Fig. 11 illustrates the effect of tank volume variation on the performance of the base-system (as built). It shows that beyond 4,000 lts, the Solar Fraction increase becomes marginal.

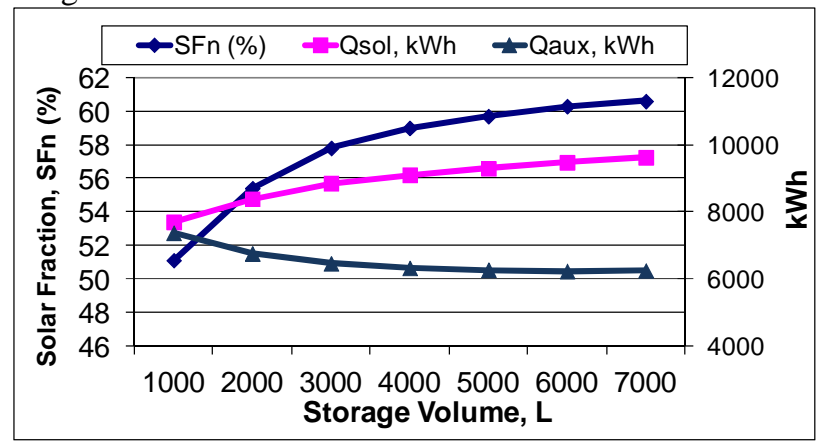

Fig. 11: Solar Fraction, solar energy collected and auxiliary heat as functions of hot water storage volume

\section{Conclusions}

Solar cooling using sorption chiller may not be a new technique, but it's still in its young age. In this work a recent installation in Northern Italy has been monitored for three weeks. A rather satisfactory performance has been recorded.

Numerical simulation using Polysun are in good agreement with experimental results.

A multiple parametric simulation of the system, based on the validated numerical model, has been carried on with the present configuration and standard meteo data (TRY). Output revealed some concrete possibilities of enhancing the performance of the system, which could have been considered during design and installation stages.

The analysis has underlined the strong importance of a well balanced design, that should cover in depth the nonconverging scopes of improving solar system efficiency, reducing tank volume, simplifying heat rejection circuit and improving chiller performance.

\section{Acknowledgement}

Validation of monitoring system output with certified portable instruments has been performed by Jacopo Toniolo, whom the authors heartily thank for this.

The work has received practical support by IPLA organization, gratefully acknowledged.

\section{References}

[1] H-M. Henning "Solar assisted air conditioning of buildings - an overview", Applied Thermal Engineering, Vol.27 (2007) pp.1734-1749

[2] J.A.Duffie, W.A.Beckman, Solar engineering of thermal process, Wiley, New york $3^{\text {rd }}$ ed. (2005), pp. 588-617

[3] F.Agyenim, I.Knight, M.Rhodes "Design and experimental testing of the performance of an outdoor $\mathrm{LiBr} / \mathrm{H} 2 \mathrm{O}$ solar thermal absorption cooling system with a cold store", Solar Energy, Vol. 84 (2010) pp.735-744

[4] L. Schnabel, M. Tatlier, F. Schmidt, A. E. Senatalar "Adsorption kinetics of zeolite coatings directly crystallized on metal supports for heat pump applications (adsorption kinetics of zeolite coatings)", Applied Thermal Engineering Vol. 30 (2010) pp.1409-1416 